Article

\title{
Low Level of Allergens in the Argentinean Plant Zuccagnia punctata Cav.: Screening and Quality Control of North-Western Propolis Using an LC-DAD-QTOF System
}

\author{
Eliana Rita Solorzano, Iole Maria Di Gangi, Marco Roverso, Gabriella Favaro, Sara Bogialli *(D) \\ and Paolo Pastore \\ Department of Chemical Sciences, University of Padua, Via Marzolo, 1, 35131 Padova, Italy \\ * Correspondence: sara.bogialli@unipd.it; Tel.: +39-049-8275207
}

Received: 18 July 2019; Accepted: 25 August 2019; Published: 29 August 2019

Featured Application: The proposed screening approach empowers the propolis quality control in terms of its potential sensitizing ability, also highlighting other botanical sources.

\begin{abstract}
North-western Argentinean propolis (NAP), having promising bioactivity, was recently included into the National Food Code. Zuccagnia punctata Cav., a native shrub of north-western Argentina, is one of the prevalent botanical sources of NAPs, but no information on its allergenic constituents was available so far. A liquid chromatography-diode array detector -quadrupole-time of flight system (LC-DAD-QTOF) was used as a screening method for the reliable identification of sensitizing agents belonging to caffeic acid derivatives in Z. punctata and in two NAPs collected in the provinces of Catamarca and Tucumán. Caffeic acid phenethyl ester, one of the most active allergens in propolis, was never detected in either Z. punctata or NAP. Among 31 sensitizers, only geranyl caffeate was alleged in Z. punctata as $<10 \%$ of its major constituent, whereas three caffeic acid derivatives with strong allergenic effect, i.e., geranyl, pentenyl, and benzyl caffeates, occurred in NAP samples ( $29 \%-36 \%$ of the Z. punctata major constituent), indicating other minor botanical sources. However, the high content of chalcones and flavonoids ascribed to Z. punctata significantly contributes to the antiallergenic and antioxidant character of these NAPs. This peculiar chemical profile depends on the extremophile condition in which this shrub grows and suggests other studies to characterize such raw materials for oral and topical formulations.
\end{abstract}

Keywords: allergenic agents; caffeic acid derivatives; Zuccagnia punctata Cav.; north-western Argentinean propolis; LC-DAD-QTOF

\section{Introduction}

Propolis is a naturally occurring material mainly consisting of vegetal resins mixed with beeswax. This material is used as a building element for covering internal walls of hives, as its antioxidant and antimicrobial properties are able to maintain an aseptic area inside the hive [1,2]. Because of its widespread spectrum of bioactivities, propolis is increasingly used for manufacturing nutraceutical products, which are perceived as natural medicines. The chemical composition of propolis is quite variable, thus its standardization and quality control are essential. Literature about the quality control of propolis has highlighted the importance of knowing the botanical origin [3] and determining toxic contaminants and potential allergenic agents, mainly caffeic acid esters [4]. Poplar-type propolis is so far the most commercialized one [5] and extensive studies in terms of biological activity are available. This promoted the design of various formulations based on propolis, such as hydroalcoholic solutions, 
lotions, ointments, lip balms, cosmetics, shampoos, conditioners, and toothpastes [6]. The beneficial bioactivity reported for poplar-type propolis is mainly ascribed to a major component, the caffeic acid phenethyl ester (CAPE) $[1,5,7,8]$. However, this compound and other analogous are reported as very strong allergenic agents as they may induce contact dermatitis when applied to skin or mucous membranes [6,9-14]. From $1.2 \%$ to $6.6 \%$ of people were reported to be allergic to propolis [14], and among all the described about $50 \%$ are related to cosmetics and $25 \%$ to contact allergies in occupational exposures $[6,9,10,15]$. Indeed, caffeates were described as the main contact allergens of propolis in middle Europe, where resins excreted by poplar trees (Populus spp.) are the preferred resources for bees [11], whilst resins from birch (Betula spp.) are selected by bees in colder temperate climates [5].

In the hot arid regions of north-western Argentina, such as the Del Monte desert, the exudates from native resinous shrubs are the preferred choice for bees [16]. In this context, Larrea spp. and Zuccagnia punctata Cav. are the prevailing species [17]. The occurrence of various sensitizing effects related to poplar-type propolis use clearly compels preliminary chemical analysis before its direct use. Recently, studies on north-western Argentinean propolis (NAP) became more exhaustive in terms of description of chemical and biological properties. This increased interest is due to its introduction into the national Food Code, justified by the beneficial effects, mainly associated to its high phenolic content $[16,18,19]$. To date only the vegetal species $Z$. punctata has been reliably related with NAPs collected in Santa Maria and Amaicha del Valle ("Calchaquí Region") [20,21]. Although some new caffeates were identified in Z. punctata [21], a chemical analysis aimed to identify sensitizing agents in propolis has been never carried out.

Liquid chromatography-UV (LC-UV) analysis is commonly used for quality control of standardized propolis and plants [22]. This technique, anyway, is not suitable for the selective identification of non-target compounds present as minor components in propolis likely coming from different botanical sources. Recently, plant extracts and related foodstuffs have been characterized by LC-high resolution mass spectrometry (LC-HRMS) $[23,24]$ by means of accurate $(<5 \mathrm{ppm})$ measurements of both pseudo-molecular and fragment ions, allowing very robust assignments when standards are not available. A recent paper highlighted that the different chemical profile in terms of caffeinates and hydroxycinnamates, produced by various extraction methods and evidenced with LC-MS analysis, affects the allergenic or pharmacologic potential of the poplar propolis [25]. In this context, a peculiar source-type propolis with low allergen content can be a direct alternative to a propolis requiring an industrial processing tailored to optimize its use and quality control.

The aim of this study is to evidence the typical allergens belonging to caffeate derivatives in Z. punctata in order to gain information on the allergenic potential of Z. punctata-type propolis and on its possible direct use without any purification step. A previous optimized approach based on LC-DAD-HR tandem MS method was used to detect and identify those compounds within a propolis quality control approach, since the NAP botanical origin is still unknown. The most relevant allergenic esters will be here listed in three groups following the classification proposed by Hausen et al. [10-13], which distinguished the most relevant allergenic esters found in propolis as weak, moderate, and strong according to the responses and reactions observed in suitably treated guinea pigs. This study drives at looking for such extremophile plants with a peculiar metabolic profile for nutraceutical and pharmaceutical applications.

\section{Materials and Methods}

\subsection{Sample Collection and Extract Preparation}

Plant aerial parts (leaves and stems) and propolis samples were collected in all seasons and subsequently gathered to prepare single samples during the period 2013-2015. Propolis samples were collected from Santa Maria city (Catamarca province) and Amaicha del Valle city (Tucumán province), both sited in the "Del Monte" phytogeographical region. Propolis collected in Santa Maria 
and Amaicha del Valle were previously related to the Z. punctata shrub [21]. The vegetal species was authenticated in the Universidad Nacional de Tucumán and voucher specimen (Z. punctata: LIL 612170) was deposited at the Herbarium of Fundación Miguel Lillo (Tucumán, Argentina).

All samples were prepared according to Solórzano et al. [16,21]. Serial dilutions of various extracts were prepared in order to avoid the saturation phenomena of the LC-DAD-MS system, with a 50/50 $(v / v)$ methanol/water solution down to a final concentration of $20 \mu \mathrm{g} / \mathrm{mL}$. The resulting solutions were named ZP for Z. punctata, while extracts of propolis were named Santa Maria (SM) and Amaicha del Valle (AV), respectively. All solvents were of analytical grade (Sigma Aldrich, Saint Louis, MO, USA).

\subsection{Instrumental Analysis}

LC-quadrupole-time-of-flight (QTOF) analysis was performed with an HPLC system (Agilent Series 1200; Agilent Technologies, Palo Alto, CA, USA), consisting of vacuum degasser, autosampler, binary pump, and column oven coupled to both a DAD and QTOF mass analyzer (Agilent Series 6520). The analytical column was a Kinetex pentafluorophenyl $(100 \times 2.1 \mathrm{~mm}, 2.6 \mu \mathrm{m}$ particle size, Phenomenex, Italy) thermostated at $30^{\circ} \mathrm{C}$. The sample injected volume was $5 \mu \mathrm{L}$. The mobile phase components $\mathrm{A}$ and $\mathrm{B}$ were water and methanol, respectively, both acidified with $1 \mathrm{mM}$ formic acid. The eluent flow rate was $0.25 \mathrm{~mL} / \mathrm{min}$. The mobile phase gradient profile was as follows: $0-16 \mathrm{~min}, 20 \%-100 \% \mathrm{~B} ; 17-19 \mathrm{~min}$, $100 \% \mathrm{~B} ; 19-20 \mathrm{~min}, 20 \% \mathrm{~B} ; 21-27 \mathrm{~min}, 20 \% \mathrm{~B}$. DAD signals were recorded in the $210-600 \mathrm{~nm}$ range. The DAD was directly connected to a QTOF mass analyzer, giving a time shift of ca. $0.15 \mathrm{~min}$ in the MS chromatogram. The QTOF system was equipped with an electrospray ionization interface (ESI), operating in dual ESI mode and negative ESI acquisition, with the following operating parameters: capillary voltage, $3500 \mathrm{~V}$; nebulizer pressure, $35 \mathrm{psi}$; drying gas, $10 \mathrm{~L} / \mathrm{min}$; gas temperature, $350{ }^{\circ} \mathrm{C}$; fragmentor voltage, $120 \mathrm{~V}$; skimmer $65 \mathrm{~V}$. The QTOF calibration was performed daily with the manufacturer's solution. In all chromatographic runs the signal at $m / z 112.9856$ was set as the reference mass. The instrument provided a typical resolving power (FWHM) of about 18,000 at $\mathrm{m} / \mathrm{z}$ 311.0805. Mass spectra at MS and MS/MS level were recorded over the range 80-1000 $\mathrm{m} / \mathrm{z}$ with a scan rate of $4 \mathrm{spectra} / \mathrm{s}$, and $50-1000 \mathrm{~m} / z$ with a scan rate of 6 spectra/s, respectively. Collision energies were set within the range 15-30 eV. Bioactive compounds previously identified in Z. punctata [21] and caffeic acid derivatives classified by Hausen et al. [10-13] were used as a list of preferred precursor ions for the auto MS analysis with a tolerance of $20 \mathrm{ppm}$ (total cycle of $1.3 \mathrm{~s}, 6$ compounds per cycle, isolation width of $4 \mathrm{u}$, active mass exclusion enabled after 30 spectra and $0.3 \mathrm{~min}$, absolute and relative precursor threshold 1000 counts and $0.001 \%$, respectively). For the post-run analysis, the $[\mathrm{M}-\mathrm{H}]^{-}$signals were processed with a tolerance of $10 \mathrm{ppm}$ in HRMS full scan mode and their identification was then confirmed mainly by comparing the obtained fragmentation patterns and UV spectra with data reported in the literature or specific MS databases such as Massbank (http://www.massbank.jp/?lang=en) and mzCloud $^{\text {TM }}$ (https://www.mzcloud.org/). Mass spectra acquisition and data analysis were processed with MassHunter Workstation B 06.00 software (Agilent Technologies, Palo Alto, CA, USA).

\section{Results}

The hyphenated system LC-DAD-QTOF provided two independent pieces of useful information on caffeic acid derivatives. A double screening process is possible based on the typical UV absorbance $(\lambda=270$ and $360 \mathrm{~nm})$ and on the accurate measurements of pseudomolecular ions corresponding to the selected compounds. LC-UV was used as the reference protocol for screening caffeic acid derivatives, also giving a rough indication of the relative abundance, as the molar responses are comparable for caffeic acid derivatives. As a matter of fact, we used the MS response for its higher selectivity and sensitivity, as several compounds were co-eluted in UV and minor components were not detected, as shown in Figure 1. The presence of potentially sensitizing agents, as evaluated by Hausen et al. [10-13] in guinea pigs or in human case studies, and relevant phenolic compounds ascribed to Z. punctata were investigated in plant and propolis extracts. Results are reported in Table 1, using the notation $\mathbf{s}$ for strong, $\mathbf{m}$ for moderate, $\mathbf{w}$ for weak, and ne for not established allergenic potential. For the 
sake of simplicity, conventional diagnostic ions are often reported in the text without decimal digits though accurate measurements were recorded. The typical MS fragmentation scheme of caffeic acid derivatives is extensively described in the literature [26-28] — caffeate esters generally produce diagnostic MS fragment ions at $\mathrm{m} / \mathrm{z} 179(\mathrm{~m} / \mathrm{z} 179.0350)$ as base peak, and at $\mathrm{m} / \mathrm{z} 135(\mathrm{~m} / \mathrm{z} 135.0452)$ corresponding to $\left[179-\mathrm{CO}_{2}\right]^{-}$. Their related radical ions at $\mathrm{m} / \mathrm{z} 178,134$, and 161 were also reported as base peaks when a benzyl moiety is present, such as for the compound (s4), as shown in Figure S1 in the supplementary material, ascribed to benzyl caffeate. Z. punctata was previously characterized, and the propolis here analyzed, were demonstrated to be Zuccagnia-type [21]. Thus, the major biomarker of Z. punctata, i.e., $4^{\prime}$-hydroxy-2'-methoxydihydrochalcone (ne3), was taken as the reference compound and the abundance of caffeic acid derivatives was expressed as a relative percentage. Many of those compounds were not detected as precursor ions at the MS level. Other compounds, like vanillin (w10) or ferulic acid (w17), were detected with very low counts at the MS level so that their fragmentation was not possible. In this case the correct identification was not allowed and their presence in the samples was not considered confirmed.

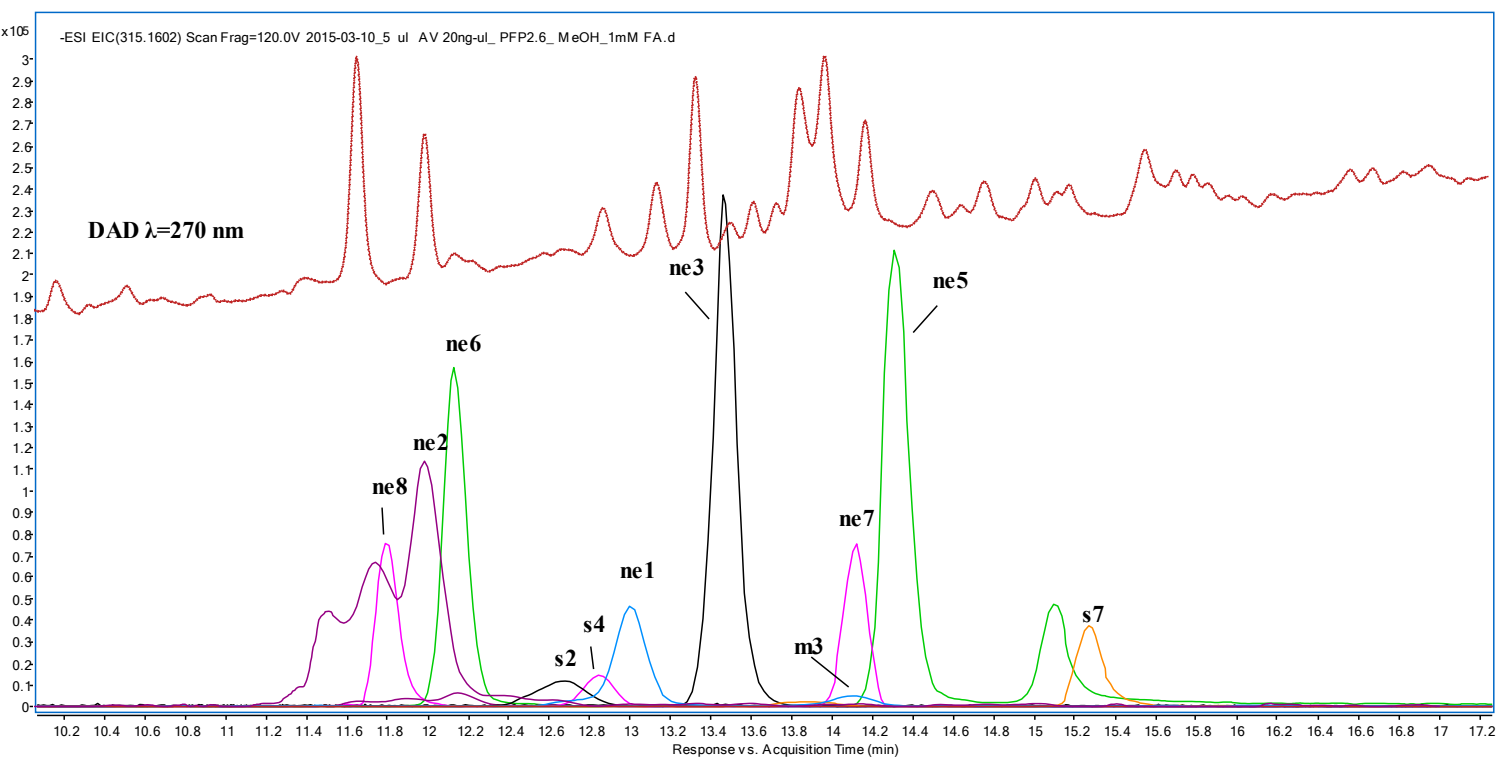

Figure 1. Chromatograms of the diode array detector (DAD) profile at $270 \mathrm{~nm}$ and extracted ion (accuracy $10 \mathrm{ppm}$ ) of the $[\mathrm{M}-\mathrm{H}]^{-}$with the relative intensities of allergenic agents and major constituents described in Table 1, identified in Amaicha del Valle propolis. In detail: (s2) = prenyl caffeates; (s4) = benzyl caffeate; (s7) = geranyl caffeate; $(\mathbf{m} 3)$ = cinnamyl caffeate; (ne1) = 1-methyl-3-(4'-hydroxyphenyl)-propyl caffeic acid ester; (ne2) = 1-methyl-3-( $3^{\prime}, 4^{\prime}$-dihydroxyphenyl)-propyl caffeic acid ester; (ne3) = $4^{\prime}$-hydroxy-2'-methoxydihydrochalcone; (ne5) = 2' $4^{\prime}$-dihydroxychalcone; (ne6) = 7-hydroxyflavanone; (ne7) $=2^{\prime}, 4^{\prime}$-dihydroxy-3'-methoxychalcone; (ne8) = 7-hydroxy-8-methoxyflavanone, where s means strong, $\mathbf{m}$ moderate and ne not established allergenic potential. A shift of about 0.15 min occurred between UV and mass spectrometric analysis. 
Table 1. Results obtained from liquid chromatography-high resolution tandem mass spectrometric analysis of Zuccagnia punctata (ZP) and two types of propolis (Santa Maria (SM) and Amaicha del Valle (AV)), expressed as a relative percentage with respect to the most abundant compound, which was (ne3) for ZP. Sensitizing agents were selected and classified according to Hausen et al. [10-13]. The precursor ions [M-H] ${ }^{-}$were identified with accuracies always $<5$ ppm. tr stands for retention times and nd for not detected. NDGA and MNDGA stand for nordihydroguaiaretic acid and 3'-methyl-nordihydroguaiaretic acid, respectively.

\begin{tabular}{|c|c|c|c|c|c|c|c|}
\hline \multirow{2}{*}{$\mathrm{N}$} & \multirow{2}{*}{$\operatorname{tr}$} & \multirow{2}{*}[\mathrm{M}-\mathrm{H}]{$^{-}$} & \multirow{2}{*}{ Compounds } & \multirow{2}{*}{ Fragments and Relative Abundances (\%) } & \multicolumn{3}{|c|}{ Samples } \\
\hline & & & & & ZP & SM & AV \\
\hline \multicolumn{8}{|c|}{ Strong sensitizing agents (s) } \\
\hline s1 & & 283.0976 & CAPE & nd & & & \\
\hline s2 & 12.62 & 247.0976 & prenyl caffeate a & 247.0976 (14); 179.0350 (21); 178.0272 (10); 161.0244 (7); 135.0452 (27); 134.0373 (100) & nd & $8.8^{\mathrm{a}}$ & $8.8^{\mathrm{a}}$ \\
\hline s3 & & 383.2228 & farnesyl caffeate & nd & & & \\
\hline s4 & 12.92 & 269.0819 & benzyl caffeate & 269.0819 (5); 178.0272 (5); 161.0244 (13); 135.0452 (11); 134.0373 (100); 80.9982 (21) & nd & 2.3 & 8.0 \\
\hline s5 & & 283.0976 & benzyl isoferulate & nd & & & \\
\hline s6 & & 227.0714 & benzyl salicylate & nd & & & \\
\hline s7 & 15.33 & 315.1602 & geranyl caffeate & 315.1602 (8); 179.035 (12); 178.0272 (10); 134.0373 (100); 133.0289 (8); 135.0452 (8) & 9.4 & 17.8 & 18.9 \\
\hline \multicolumn{8}{|c|}{ Moderate sensitizing agents $(m)$} \\
\hline $\mathrm{m} 1$ & & 283.0976 & coniferyl benzoate & nd & & & \\
\hline $\mathrm{m} 2$ & & 213.0557 & resorcinol monobenzoate & nd & & & \\
\hline m3 & 14.10 & 295.0976 & cinnamyl caffeate & 295.0976 (77); 178.0272 (42); 135.0452 (13); 134.0373 (100) & nd & 1.4 & 3.6 \\
\hline m4 & 6.78 & 193.0506 & methyl caffeate & $193.0510(24) ; 178.0272(48) ; 149.0608$ (24); $134.0373(17)$ & nd & 0.5 & nd \\
\hline m5 & & 179.0713 & coniferyl alcohol & nd & & & \\
\hline m6 & & 297.1132 & phenylethyl isoferulate & nd & & & \\
\hline $\mathrm{m} 7$ & 15.99 & 369.1344 & acetate of phenylethyl caffeate & - & nd & $\mathrm{b}$ & $\mathrm{b}$ \\
\hline \multicolumn{8}{|c|}{ Weak to Negative sensitizing agents(w) } \\
\hline w1 & & 283.0976 & benzyl ferulate & nd & & & \\
\hline w2 & & 237.0931 & benzyl cinnamate & nd & & & \\
\hline w3 & & 263.1077 & cinnamyl cinnamate & nd & & & \\
\hline w4 & & 261.1132 & 3-methyl-2-butenyl isoferulate & nd & & & \\
\hline w5 & & 161.0608 & methyl cinnamate & nd & & & \\
\hline w6 & & 211.0764 & benzyl benzoate & nd & & & \\
\hline w7 & & 179.0350 & caffeic acid & nd & & & \\
\hline w8 & & 122.1213 & benzoic acid & nd & & & \\
\hline w9 & & 181.0506 & dihydrocaffeic acid & nd & & & \\
\hline w10 & 14.24 & 151.0401 & vanillin & - & $\mathrm{b}$ & $\mathrm{b}$ & $\mathrm{b}$ \\
\hline w11 & & 221.1911 & farnesol & nd & & & \\
\hline w12 & & 309.1132 & cynnamyl isoferulate & nd & & & \\
\hline w13 & & 133.0659 & $\begin{array}{l}\text { cynnamic alcohol } \\
\text { con }\end{array}$ & nd & & & \\
\hline w14 & & 107.0502 & benzyl alcohol & nd & & & \\
\hline w15 & & 439.1551 & coniferyl dicinnamate & nd & & & \\
\hline w16 & & 267.0663 & tectochrysin & - & nd & $\mathrm{b}$ & $\mathrm{b}$ \\
\hline w17 & & 193.0506 & ferulic acid & - & nd & $\mathrm{b}$ & $\mathrm{b}$ \\
\hline
\end{tabular}


Table 1. Cont.

\begin{tabular}{|c|c|c|c|c|c|c|c|}
\hline \multirow{2}{*}{$\mathbf{N}$} & \multirow{2}{*}{$\operatorname{tr}$} & \multirow{2}{*}[\mathrm{M}-\mathrm{H}]{$^{-}$} & \multirow{2}{*}{ Compounds } & \multirow{2}{*}{ Fragments and Relative Abundances (\%) } & \multicolumn{3}{|c|}{ Samples } \\
\hline & & & & & ZP & SM & $\mathrm{AV}$ \\
\hline \multicolumn{8}{|c|}{ Major components, not established allergenic potential (ne) } \\
\hline ne1 & 13.02 & 327.1238 & 1-methyl-3-(4'-hydroxyphenyl)-propyl caffeic acid ester & 327.1238 (100); 179.035 (16); 163.0401 (20); 135.0452 (10); 134.03731 (7); 119.0502 (7) & 21.8 & 22.8 & 25.9 \\
\hline ne2 & 11.91 & 343.1187 & 1-methyl-3-(3',4'-dihydroxyphenyl)-propyl caffeic acid ester & 343.1187 (100); 179.035 (30); 181.0506 (3); 163.0765 (3); 161.0244 (4); 135.0452 (22) & 29.0 & 34.8 & 54.7 \\
\hline ne3 & 13.53 & 255.1027 & $4^{\prime}$-hydroxy-2'-methoxydihydrochalcone & 255.1027 (28); 239.0713 (2); 149.0244 (9); 136.0165 (100); 121.0290 (2); 108.0216 (31); 80.0267 (5) & 100 & 61.2 & 85.6 \\
\hline ne4 & 13.01 & 241.0875 & $2^{\prime}, 4^{\prime}$-dihydroxydihydrochalcone & 241.0870 (100); 223.0764 (6); 197.0971 (15); 150.0322 (98); 135.0087 (59); 122.0373 (69); 109.0295 (67); 91.0189 (36) & 23.6 & 19.0 & 21.5 \\
\hline ne5 & 14.38 & 239.0714 & $2^{\prime}, 4^{\prime}$-dihydroxychalcone & $239.0714(100) ; 197.0608(20) ; 135.0088(37) ; 91.0189(15)$ & 96.3 & 68.0 & 95.0 \\
\hline ne6 & 12.19 & 239.0714 & 7-hydroxyflavanone & $239.0714(100) ; 197.0608$ (60); $135.0088(37) ; 91.0189(16)$ & 63.9 & 34.9 & 46.1 \\
\hline ne7 & 14.13 & 269.0819 & $2^{\prime}, 4^{\prime}$-dihydroxy-3'-methoxychalcone & 269.0819 (18); 254.0585 (71); 149.9959 (100); 122.0009 (9); 106.0060 (21); 94.0060 (27) & 34.7 & 22.9 & 31.2 \\
\hline ne8 & 11.80 & 269.0819 & 7-hydroxy-8-methoxyflavanone & 269.0819 (18); 254.0585 (71); 149.9959 (100); 122.0009 (9); 106.0060 (21); 94.0060 (27) & 22.4 & 13.9 & 27.1 \\
\hline ne9 & 13.82 & 301.1445 & NDGA & $301.1445(100) ; 273.1132(4) ; 122.0373(78)$ & nd & 1.5 & nd \\
\hline ne10 & & 315.1602 & MNDGA & nd & & & \\
\hline ne11 & 13.41 & 285.1496 & 4-[4-(4-hydroxy-phenyl)-2,3-dimethyl butyl] benzene-1,2-diol & 285.1496 (100); $122.0973(32)$ & nd & 0.2 & 0.1 \\
\hline
\end{tabular}

${ }^{a}$ Isomeric pentenyl caffeates-A tentative assignment can be 3-methyl-2-butenyl caffeate or 2-methyl-2-butenyl caffeate; ${ }^{\mathrm{b}}$ signal present as pseudomolecular ion with very low counts, not fragmented in tandem MS. 


\subsection{Caffeic Acid Derivatives with Known Sensitizing Properties}

\subsubsection{First Group: Strong Sensitizing Agents}

A percentage of $0.01 \%$ of $\mathrm{CAPE}$, a typical biomarker present in poplar propolis, produced strong reactions as well as $1 \%$ of propolis [11]. Indeed, CAPE (s1) is absent in both Z. punctata and related propolis. Other isomers having the same $[\mathrm{M}-\mathrm{H}]^{-}$at $\mathrm{m} / \mathrm{z} 283.0976$ and with different sensitizing character, like benzyl isoferulate (s5), coniferyl benzoate (m1), and benzyl ferulate (w1) are absent as well. Another important allergenic component described in the literature is 3-methyl-2-butenyl (prenyl) caffeate (s2) $\left([\mathrm{M}-\mathrm{H}]^{-}\right.$at $\left.\mathrm{m} / \mathrm{z} 247.0976\right)$. This is one of the three isomeric forms of pentenyl caffeic acid esters, being 3-methyl-2-butenyl the strongest sensitizer followed by 3-methyl-3-buthenylcaffeate and 2-methyl-2-buthenyl-caffeate. In the reported experimental conditions, a single chromatographic peak, probably containing the three isomeric forms, was found only in propolis samples, as shown in Figure 1. This precursor ion at $m / z 247.0976$ exhibited the daughter ion at $\mathrm{m} / \mathrm{z} 134$ as base peak and negligible signals at $\mathrm{m} / \mathrm{z} 161$ and 178. According to bibliographic data [29], when a fragment ion at $m / z 134$ is the base peak, as shown in Figure S2 in the supplementary material, the identification of 3-methyl-2-butenyl caffeate (s2) or 2-methyl-2-butenyl caffeate can be tentatively given. Another compound identified in propolis was the benzyl caffeate (s4) (already described in NAPs [20]). These two compounds accounted for a maximum of about $9 \%$ each one in $\mathrm{AV}$, whilst they were not detected in $\mathrm{ZP}$.

Differently, a compound with $m / z 315.1602$ (Figure S3), already assigned to geranyl caffeate (s7) [21], was detected in both Z. punctata and propolis at various relative ratios. Geranyl caffeate was described as a strong sensitizer in experiments with guinea pigs [10] and, if confirmed, so far it is the unique relevant allergenic substance determined in Z. punctata $(9.4 \%)$.

\subsubsection{Second Group: Moderate Sensitizing Agents}

Only two compounds belonging to this group were detected and characterized in the analyzed propolis-cinnamyl caffeate (m3), with $[\mathrm{M}-\mathrm{H}]^{-}$at $\mathrm{m} / \mathrm{z} 295.0976$, and methyl caffeate $(\mathbf{m} 4)$, with $[\mathrm{M}-\mathrm{H}]^{-}$ at $m / z$ 193.0506. The assignments were proposed considering that the signal commonly referred to hydroxylated alcohol moieties, e.g., benzyl, prenyl, or cinnamyl groups, was missing. A low amount of (m3) was found in SM and AV, whilst methyl caffeate (m4) was barely appreciable in SM. Low signals corresponding to the acetate of phenylethyl caffeate $(\mathrm{m} 7)$ ion were obtained, but not characterized, in propolis. Also, in this case none of the compounds belonging to this group is present in $\mathrm{ZP}$.

\subsubsection{Third Group: Weak to Negative Sensitizing Agents}

The third group contains molecules having mild or not significant allergenic effects. Among these, vanillin (w10), displayed a pseudomolecular ion within the set accuracy both in plant and propolis. Nevertheless, signals recorded were so low that no fragmentation was possible. Similar findings occurred for tectochrysin (w16) and ferulic acid (w17) in propolis, whereas these compounds were not detected in Z. punctata.

\subsection{Potential Allergenic/Antiallergenic Compounds in NAPs}

Table 1 lists molecules already described as major constituents of Z. punctata [21] having possible allergenic or anti-allergenic properties. From our results only one compound among the two groups of strong or moderate sensitizing agents, i.e., geranyl caffeate (s7), was alleged at significant percentage in the north-western Argentinean native resinous plant Z. punctata. The contextual and remarkable content of chalcones-type compounds with promising anti-allergenic effects suggests that the use of this native shrub can be further tested and studied for manufacturing phyto-medicines for pharmaceutical applications.

On the other hand, NAP samples were characterized by a large contribution of (s7), and moderate or low percentages of (s2), (s4), (m3), and (m4). These allergenic agents identified in propolis, 
except geranyl caffeate, can be likely associated to other botanical sources. Since prenyl caffeate (s2) and cinnamyl caffeate (m3) are biomarkers of poplar [30], its resin can be present in the analyzed propolis. As the Larrea spp. is widespread in the Del Monte region, the pseudomolecular ions related to its biomarkers, namely the lignans nordihydroguaiaretic acid (NDGA) and 3'-methyl-nordihydroguaiaretic acid (MNDGA), were searched in non-target mode. NDGA (ne9) was detected in the SM sample, whereas the typical fragmentation pattern of MNDGA (ne10) was not observed for the precursor ion at $\mathrm{m} / \mathrm{z} 315.1602$ that was assigned to geranyl caffeate. Another signal with fragment ions typical of the pattern of lignans was found in both types of propolis at very low levels. It was attributed to 4-[4-(4-hydroxy-phenyl)-2,3-dimethyl butyl] benzene-1,2-diol (ne11), a compound reported elsewhere from L. nitida [31]. It is noteworthy that we found low levels of those compounds notwithstanding Larrea spp. is the most present native genus in the Del Monte region. Although lignans were not described by Hausen et al. [10-13], it is known that some of them are promising inhibitors of allergic mediators [32,33]. Anyway, topical administration of NDGA was reported to cause sensitizing reactions [34], whilst no information about the sensitizing properties of (ne11) was reported. Taking into consideration the low contribution of Larrea spp. to the propolis composition, its allergenic effects can be considered negligible.

In regard to compounds with still uncertain sensitizing ability listed in Table 1, the most abundant esters were the 1-methyl-3-(4'-hydroxyphenyl)-propyl caffeic acid ester (ne1) and 1-methyl-3-( $3^{\prime}, 4^{\prime}$-dihydroxyphenyl)-propyl caffeic acid ester (ne2), detected in the largest amount in propolis, and previously reported in Z. punctata by Svetaz [35]. Since the catechol moiety was found to increase the sensitizing capacity, esters of the caffeic acid are generally considered potentially allergenic compounds differently from the esters of the ferulic, cinnamic, and coumaric acids. Although (ne1) and (ne2) share catechol moieties, no specific information was found about their allergenic potential, whilst these esters exhibited an antioxidant activity from 5 to 16 folds higher than the commercial available antioxidant BHT (butylated hydroxytoluene) [36].

Finally, for a correct assessment of the allergenic potential of NAPs, their major components such as flavanones (ne6), (ne8), chalcones (ne5), (ne7), and dihydrochalcones (ne3), (ne4) [20,21] have to be considered as they have anti-allergic activities [37]. Figure 1 shows a chromatogram representing the significant major components (ne1), (ne2), (ne3), (ne5), (ne6), and (ne8) compared to the identified allergenic agents (s2), (s4), (s7), and (m3) for the AV sample. The DAD profile was unable to highlight minor compounds belonging to caffeic acid derivatives, whilst MS analysis succeeded in evaluating the low contribution of the strong or moderate sensitizing agents (s2), (s4), and (m3). Also, 2' $4^{\prime}$-dihydroxy-chalcone (ne5), was one of the biomarkers proposed for Z. punctata, and the major component of $\mathrm{SM}$ and $\mathrm{AV}$ propolis.

Naringenin-chalcone demonstrated inhibitory effects on histamine release from mast cells [38]. In addition, several chalcone glycosides isolated from aerial parts of Brassica rapa (Brassicaceae), significantly suppressed the degranulation stimulated by antigens from mast cells and basophils [39]. Indeed, the effectiveness of moisturizers based on herbal extracts containing chalcones for treatment of atopic dermatitis was comparable to hydrocortisone-based lotions [40]. Tanaka suggested that an appropriate intake of flavonoids in allergic models such as asthma, atopic dermatitis, anaphylaxis, and food allergy demonstrated relevant beneficial effects [37], which can be effectively evaluated by a set of biological assays. As the chemical composition of this extremophile plant is still partially unknown, the study of the biological effects of Z. punctata and its related propolis is currently under investigation. As a matter of fact, this paper describes for the first time that Z. punctata is a propolis source relevant for its low content of such allergenic compounds. Such considerations support the general healthful bioactivity of NAPs. Anyway, such a peculiar chemical profile, i.e., the substantial absence of the typical poplar allergens and the high content of chalcones/flavonoids must be verified in the context of the quality control protocols. The relative abundance of the active compounds coming from other botanical sources must be monitored to connect this Zuccagnia-type propolis to its specific biological activity [5], and to avoid the contamination with those potential allergenic compounds that 
can have adverse results for human health. In this framework, the LC-DAD-HRMS technique was suitable to verify the presence of known sensitizing agents belonging to the caffeic acid derivatives in Z. punctata and in NAPs, also providing a sensitive method for quality control of the botanical origin. An in-depth analysis of plants and plant-derived products growing in such peculiar ecotypes can enlarge the knowledge of their metabolism and favor a tailored human usage.

Supplementary Materials: The following are available online at http://www.mdpi.com/2076-3417/9/17/3546/s1, Figure S1: tandem mass spectrometric spectrum of the compound (s4), identified as benzyl caffeate in Amaicha del Valle propolis, Figure S2: tandem mass spectrometric spectrum of the compound (s2), identified as prenyl caffeates in Amaicha del Valle propolis, Figure S3: tandem mass spectrometric spectrum of the compound (s7), identified as geranyl caffeate in Santa Maria propolis.

Author Contributions: Conceptualization, E.R.S.; Data curation, I.M.D.G; Formal analysis, E.R.S.; Funding acquisition, P.P.; Investigation, M.R. and S.B.; Methodology, M.R. and S.B.; Resources, G.F.; Supervision, S.B. and P.P.; Visualization, G.F.; Writing—original draft, E.R.S. and S.B.; Writing—review \& editing, P.P.

Funding: This research was partially supported by the research fellowship "Aldo Gini Foundation".

Conflicts of Interest: The authors declare no conflict of interest.

\section{References}

1. Bankova, V.; Popova, M.; Bogdanov, S.; Sabatini, A.G. Chemical composition of European propolis: Expected and unexpected results. Zeitschrift fur Naturforschung C J. Biosci. 2002, 57, 530-533. [CrossRef]

2. Langenheim, J.H. Plant Resins: Chemistry, Evolution, Ecology, Ethnobotany; Timber Press: Cambridge, UK, 2003; ISBN 0881925748.

3. Sforcin, J.M.; Bankova, V. Propolis: Is there a potential for the development of new drugs? J. Ethnopharmacol. 2011, 133, 253-260. [CrossRef] [PubMed]

4. Woisky, R.G.; Salatino, A. Analysis of propolis: Some parameters and procedures for chemical quality control Analysis of propolis: Some parameters and procedures for chemical quality control. J. Apic. Res. 1998, 37, 99-105. [CrossRef]

5. Bankova, V. Chemical diversity of propolis and the problem of standardization. J. Ethnopharmacol. 2005, 100, 114-117. [CrossRef] [PubMed]

6. Walgrave, S.E.; Warshaw, E.M.; Glesne, L.A. Allergic contact dermatitis from propolis. Dermatitis 2005, 16, 209-215. [PubMed]

7. Murtaza, G.; Karim, S.; Akram, M. Caffeic Acid Phenethyl Ester and Therapeutic Potentials. Biomed Res. Int. 2014, 2014, 145342. [CrossRef] [PubMed]

8. Russo, A.; Longo, R.; Vanella, A. Antioxidant activity of propolis: Role of caffeic acid phenethyl ester and galangin. Fitoterapia 2002, 73, S21-S29. [CrossRef]

9. BasistaSołtys, K. Allergy to Propolis in Beekeepers-A Literature Review. Occup. Med. Health Aff. 2013. [CrossRef]

10. Hausen, B.M.; Evers, P.; Stüwe, H.-T.; König, W.A.; Wollenweber, E. Propolis allergy (IV) Studies with further sensitizers from propolis and constituents common to propolis, poplar buds and balsam of Peru. Contact Dermat. 1992, 26, 34-44. [CrossRef] [PubMed]

11. Hausen, B.M. Evaluation of the main contact allergens in propolis (1995 to 2005). Dermatitis 2005, 16, 127-129. [PubMed]

12. Hausen, B.M.; Wollenweber, E. Propolis allergy: (III). Sensitization studies with minor constituents. Contact Dermat. 1988, 19, 296-303. [CrossRef] [PubMed]

13. Oliwiecki, S.; Beck, M.H.; Hausen, B.M. Occupational allergic contact dermatitis from caffeates in poplar bud resin in a tree surgeon. Contact Dermat. 1992, 27, 127-128. [CrossRef]

14. Pobiega, K.; Kraśniewska, K.; Gniewosz, M. Application of propolis in antimicrobial and antioxidative protection of food quality-A review. Trends Food Sci. Technol. 2019, 83, 53-62. [CrossRef]

15. Gambichler, T.; Boms, S.; Freitag, M. Contact dermatitis and other skin conditions in instrumental musicians. BMC Dermatol. 2004, 4, 3. [CrossRef] [PubMed]

16. Solórzano, E.; Vera, N.; Cuello, S.; Ordoñez, R.; Zampini, C.; Maldonado, L.; Bedascarrasbure, E.; Isla, M.I. Chalcones in bioactive Argentine propolis collected in arid environments. Nat. Prod. Commun. 2012, 7, 879-882. [CrossRef] [PubMed] 
17. Villagra, P.E.; Giordano, C.; Alvarez, J.A.; Cavagnaro, J.B.; Guevara, A.; Carmen, S.; Passera, C.B.; Greco, S.E. Ser planta en el desierto: Estrategias de uso de agua y resistencia al estrés hídrico en el Monte Central de Argentina. Ecol. Austral 2011, 21, 29-42.

18. Vera, N.; Solorzano, E.; Ordoñez, R.; Maldonado, L.; Bedascarrasbure, E.; Isla, M.I. Chemical composition of Argentinean propolis collected in extreme regions and its relation with antimicrobial and antioxidant activities. Nat. Prod. Commun. 2011, 6, 823-827. [CrossRef]

19. Yao, L.H.; Jiang, Y.M.; Shi, J.; Tomás-Barberán, F.A.; Datta, N.; Singanusong, R.; Chen, S.S. Flavonoids in food and their health benefits. Plant Foods Hum. Nutr. 2004, 59, 113-122. [CrossRef]

20. Agüero, M.B.; Gonzalez, M.; Lima, B.; Svetaz, L.; Sánchez, M.; Zacchino, S.; Feresin, G.E.; Schmeda-Hirschmann, G.; Palermo, J.; Daniel Wunderlin, D.; et al. Argentinean propolis from Zuccagnia punctata cav. (Caesalpinieae) exudates: Phytochemical characterization and antifungal activity. J. Agric. Food Chem. 2010, 58, 194-201.

21. Solorzano, E.R.; Bortolini, C.; Bogialli, S.; Di Gangi, I.M.; Favaro, G.; Maldonado, L.; Pastore, P. Use of a LC-DAD-QTOF system for the characterization of the phenolic profile of the argentinean plant Zuccagnia punctata and of the related propolis: New biomarkers. J. Funct. Foods 2017, 33, 425-435. [CrossRef]

22. De Rijke, E.; Out, P.; Niessen, W.M.; Ariese, F.; Gooijer, C.; Brinkman, U.A. Analytical separation and detection methods for flavonoids. J. Chromatogr. A 2006, 1112, 31-63. [CrossRef] [PubMed]

23. Wu, H.; Guo, J.; Chen, S.; Liu, X.; Zhou, Y.; Zhang, X.; Xu, X. Recent developments in qualitative and quantitative analysis of phytochemical constituents and their metabolites using liquid chromatography-mass spectrometry. J. Pharm. Biomed. Anal. 2013, 72, 267-291. [CrossRef] [PubMed]

24. Steinmann, D.; Ganzera, M. Recent advances on HPLC/MS in medicinal plant analysis. J. Pharm. Biomed. Anal. 2011, 55, 744-757. [CrossRef] [PubMed]

25. Saftić, L.; Peršurić, Ž.; Kraljević Pavelić, S. LC-QQQ and LC-QTOF MS methods for comprehensive detection of potential allergens in various propolis extracts. Eur. Food Res. Technol. 2019, 1-15. [CrossRef]

26. Medana, C.; Carbone, F.; Aigotti, R.; Appendino, G.; Baiocchi, C. Selective analysis of phenolic compounds in propolis by HPLC-MS/MS. Phytochem. Anal. 2008, 19, 32-39. [CrossRef] [PubMed]

27. Jaiswal, R.; Matei, M.F.; Ullrich, F.; Kuhnert, N. How to distinguish between cinnamoylshikimate esters and chlorogenic acid lactones by liquid chromatography-tandem mass spectrometry. J. Mass Spectrom. 2011, 46, 933-942. [CrossRef] [PubMed]

28. Silva, T.; Oliveira, C.; Borges, F. Caffeic acid derivatives, analogs and applications: A patent review (2009-2013). Expert Opin. Ther. Pat. 2014, 24, 1257-1270. [CrossRef] [PubMed]

29. Gardana, C.; Simonetti, P. Evaluation of allergens in propolis by ultra-performance liquid chromatography/tandem mass spectrometry. Rapid Commun. Mass Spectrom. 2011, 25, 1675-1682. [CrossRef]

30. Wagh, V.D. Propolis: A wonder bees product and its pharmacological potentials. Adv. Pharm. Sci. 2013, 308249. [CrossRef]

31. Agüero, M.B.; Svetaz, L.; Sánchez, M.; Luna, L.; Lima, B.; López, M.L.; Zacchino, S.; Palermo, J.; Wunderlin, D.; Feresin, G.E.; et al. Argentinean Andean propolis associated with the medicinal plant Larrea nitida Cav. (Zygophyllaceae). HPLC-MS and GC-MS characterization and antifungal activity. Food Chem. Toxicol. 2011, 49, 1970-1978.

32. Chae, H.; Kang, O.; Oh, Y.; Choi, J.; Keum, J.; Kim, S.; Kim, Y.-S.; Mun, S.-H.; Shin, D.-W.; Han, S.-H.; et al. Gomisin $\mathrm{N}$ has anti-allergic effect and inhibits inflammatory cytokine expression in mouse bone marrow-derived mast cells. Immunopharmacol. Immunotoxicol. 2011, 33, 709-713. [CrossRef] [PubMed]

33. Shin, K.; Chung, H.; Kim, D.; Hwang, J.; Lee, S. Macelignan attenuated allergic lung in fl ammation and airway hyper-responsiveness in murine experimental asthma. Life Sci. 2013, 92, 1093-1099. [CrossRef] [PubMed]

34. Lambert, J.D.; Dorr, R.T.; Timmermann, B.N. Nordihydroguaiaretic acid: A review of its numerous and varied biological activities. Pharm. Biol. 2004, 42, 149-158. [CrossRef]

35. Svetaz, L.; Tapia, A.; López, S.N.; Furlán, R.L.E.; Petenatti, E.; Pioli, R.; Schmeda-Hirschmann, G.; Zacchino, S.A. Antifungal chalcones and new caffeic acids esters from Zuccagnia punctata acting against soybean infecting fungi. J. Agric. Food Chem. 2004, 52, 3297-3300. [CrossRef]

36. Ramachandra, M.S.; Subbaraju, G. V Synthesis and bioactivity of novel caffeic acid esters from Zuccagnia punctata. J. Asian Nat. Prod. Res. 2006, 8, 683-688. [CrossRef] 
37. Tanaka, T. Flavonoids for allergic diseases: Present evidence and future perspective. Curr. Pharm. Des. 2014, 20, 879-885. [CrossRef]

38. Yamamoto, T.; Yoshimura, M.; Yamaguchi, F.; Kouchi, T.; Tsuji, R.; Saito, M.; Obata, A.; Kikuchi, M. Anti-allergic activity of naringenin chalcone from a tomato skin extract. Biosci. Biotechnol. Biochem. 2004, 68, 1706-1711. [CrossRef]

39. Itoh, T.; Ninomiya, M.; Nozawa, Y.; Koketsu, M. Chalcone glycosides isolated from aerial parts of Brassica rapa L. "hidabeni" suppress antigen-stimulated degranulation in rat basophilic leukemia RBL-2H3 cells. Bioorg. Med. Chem. 2010, 18, 7052-7057. [CrossRef]

40. Udompataikul, M.; Srisatwaja, W. Comparative trial of moisturizer containing licochalcone A vs. hydrocortisone lotion in the treatment of childhood atopic dermatitis: A pilot study. J. Eur. Acad. Dermatol. Venereol. 2011, 25, 660-665. [CrossRef]

(C) 2019 by the authors. Licensee MDPI, Basel, Switzerland. This article is an open access article distributed under the terms and conditions of the Creative Commons Attribution (CC BY) license (http://creativecommons.org/licenses/by/4.0/). 